\title{
Salinomycin and its derivatives as potent RET transcriptional inhibitors for the treatment of medullary thyroid carcinoma
}

\author{
TARIQ ALQAHTANI ${ }^{1,2}$, VISHNU MUTHURAJ KUMARASAMY ${ }^{1}$, ADAM HUCZYNSSKI $^{3}$ and DAEKYU SUN ${ }^{1,4,5}$ \\ ${ }^{1}$ Department of Pharmacology and Toxicology, College of Pharmacy, University of Arizona, \\ Tucson, AZ 85721, USA; ${ }^{2}$ Department of Pharmaceutical Sciences, College of Pharmacy, \\ King Saud bin Abdulaziz University for Health Sciences, \\ Ministry of National Guard Health Affairs, Riyadh 11481, Saudi Arabia; \\ ${ }^{3}$ Faculty of Chemistry, Adam Mickiewicz University, 60-780 Poznan, Poland; \\ ${ }^{4}$ BIO5 Institute, University of Arizona, Tucson, AZ 85721; ${ }^{5}$ Arizona Cancer Center, \\ University of Arizona, Tucson, AZ 85724, USA
}

Received January 15, 2019; Accepted September 19, 2019

DOI: $10.3892 /$ ijo.2019.4916

\begin{abstract}
Rearranged during transfection kinase (RET) is a validated molecular target in medullary thyroid cancer (MTC), as activating mutations in RET are often associated with the development of MTC. The present study reports the first preclinical characterization of salinomycin and selected analogs as potent RET transcriptional inhibitors. Reverse transcription-PCR and immunoblotting revealed that salinomycin profoundly decreased RET expression in the TT human MTC cell line by inhibiting RET transcription. Moreover, salinomycin resulted in remarkable anti-proliferative activity against MTC that is driven by RET (gain of function mutation) by selectively inhibiting the intracellular PI3K/Akt/mTOR signaling pathway. Also, flow cytometry and fluorescence-activated cell sorting showed that salinomycin induces G1 phase arrest and apoptosis by reducing the expression of retinoblastoma protein, E2F1, cyclin D and CDK4. The structure-activity relationship of salinomycin was investigated in this study. Some of the salinomycin derivatives showed the ability to reduce RET expression where others fail to alter RET expression. These results suggest that the RET-suppressing effect of salinomycin may be largely attributed to disruption of the Wnt pathway, presumably through interference with the ternary LRP6-Frizzled-Wnt complex. Furthermore, these findings support the further preclinical evaluation of salinomycin and its analogs as a promising new class of therapeutic agents for the improved treatment of MTC.
\end{abstract}

Correspondence to: Dr Daekyu Sun, Department of Pharmacology and Toxicology, College of Pharmacy, University of Arizona, 1703 East Mabel Street, Tucson, AZ 85721, USA

E-mail: sun@pharmacy.arizona.edu

Key words: RET, salinomycin, medullary thyroid carcinoma, Wnt signaling

\section{Introduction}

Salinomycin is a potassium ionophore that has been isolated from Streptomyces albus and is commercially used as an anticoccidal agent in veterinary medicine (1). Salinomycin has been shown to reduce growth in several tumor cell types, including breast cancer, prostate cancer and chemotherapy-resistant cancer cells (2-5). Following a high-throughput screen of nearly 16,000 small molecules, salinomycin was found to selectively inhibit the growth of breast cancer stem cells with 100-fold higher potency than paclitaxel (6). Salinomycin has also been found to induce apoptosis in PC3 prostate cancer cells by increasing reactive oxygen species (ROS) levels and altering mitochondrial membrane depolarization through activation of the intrinsic apoptosis pathway (2). Recently, amide and ester derivatives of salinomycin have shown anti-proliferative activity against leukemia and breast cancer (7). Additionally, the effects of certain salinomycin derivatives have been shown to surpass those of cytotoxic drugs such as cisplatin and doxorubicin in LoVo/DX human colon adenocarcinoma cells that are resistant to doxorubicin (8).

Despite being relatively uncommon, medullary thyroid carcinoma (MTC) accounts for the majority of thyroid cancer-associated mortalities (9). MTC is characterized as an indolent tumor; however, it is one of the most aggressive forms of thyroid cancer in its late stages (10). MTC tumors are derived from the parafollicular cells of the thyroid gland, which normally secrete calcitonin (11). The majority of cases of MTC are sporadic, and only $25 \%$ arise as hereditary multiple endocrine neoplasia (12). Specific mutations are associated with phenotype and prognosis for both hereditary and sporadic MTC $(9,12)$. Approximately $15 \%$ of patients present distant metastasis of the tumor into the lung, bone and liver with a 10 -year survival rate of $20 \%$ (11). As in other differentiated cancers of the thyroid gland, thyroidectomy is the treatment of choice $(9,11)$. Since parafollicular cells lack iodine transporters and thyroid-stimulating hormone (TSH), traditional thyroid cancer treatments with radioactive iodine or TSH 
suppression are not effective (13). Additionally, MTC develops resistance to most cytotoxic chemotherapies. Previous studies have identified few genetic alterations that are involved in the pathogenesis of MTC (13). Rearranged during transfection proto-oncogene (RET) appears to be the primary oncogene in sporadic MTC and other types of endocrine cancer, such as papillary thyroid carcinoma (PTC) (14). KRAS, HRAS and NRAS are other common mutations, but are less common than RET (15).

RET is a single-pass transmembrane receptor tyrosine kinase that binds to glial cell line-derived neurotrophic factor and dimerizes. Upon RET dimerization, the tyrosine 1062 residue in the intra-cellular kinase domain is phosphorylated (16). RET plays a crucial role in mammalian embryonic development of the brain, peripheral nervous system, calcitonin producing C-cells and thyroid gland (14). The RET-mediated signaling pathway regulates the molecular mechanisms that are primarily responsible for biological processes including cell growth, differentiation and survival. Increase in RET expression levels is associated with cancer progression and poor survival (17). The constitutive activation of several growth-factor receptors, including RET, platelet-derived growth factor receptor, insulin-like growth factor receptor 1 and epidermal growth factor receptor (EGFR), is generally associated with the development and progression of different types of cancers (14). Knocking out RET in mouse models increases prenatal death rates, demonstrating the importance of RET signaling in early development $(18,19)$. Consequently, targeting RET in MTC using small molecule tyrosine kinase inhibitors may diminish tumor proliferation and induce apoptosis. The current standard treatment options of cabozantinib (XL184) and (ZD6474) have shown low response rates and serious side effects, which include pulmonary embolism and gastrointestinal bleeding with cabozantinib, and QT prolongation with torsade de pointes and sudden cardiac death with vandetanib (20-22). Therefore, the search for safer and more effective small molecules continues, with the aim of targeting and understanding the role of the RET proto-oncogene in MTC (14).

Activation of Wnt/ $\beta$-catenin signaling has been shown to be associated with several types of cancer, including colorectal, hepatocellular and breast cancer (23-25). It is commonly accepted that activation of Wnt signaling is a late-occurring event in thyroid cancers, particularly in anaplastic and poorly differentiated thyroid cancers (26). There is evidence to suggest that Wnt activation serves a pivotal role in the initiation of papillary thyroid carcinoma; however, the precise nature of that role is not yet fully understood $(26,27)$.

The present study demonstrated the effects of salinomycin and its analogs on RET expression, low-density lipoprotein receptor-related protein 6 (LRP6) expression and phosphorylation, as well as on their downstream pathways. It also revealed an association between RET and LRP6 expression in an MTC model for the first time, to the best of our knowledge, using salinomycin, salinomycin derivatives, Wnt inhibitors and RET small interfering RNA (siRNA). This relationship between RET and LRP6 has previously been observed in early kidney development and cystic dysplasia in an animal model (19). Finally, the unique capability of salinomycin to induce cell cycle arrest and apoptosis independently of ROS generation in MTC was demonstrated.

\section{Materials and methods}

Chemicals. Salinomycin and niclosamide (N3510) were purchased from Sigma-Aldrich (Merck KGaA). The synthesis and characterization of the 16 salinomycin derivatives were conducted as previously described $(7,28)$.

Cell culture and media. Human MTC cell lines (TT and MZ-CRC1), an immortalized normal human thyroid epithelial cell line (Nthy-ori 3-1) and papillary thyroid carcinoma cell line (K1) were obtained from the American Type Culture Collection. Cell authentication was completed for K1 using STR profiling, and the results exceeded the $80 \%$ match threshold with the $\mathrm{K} 1$ reference. $\mathrm{K} 1$ is considered as a subpopulation of Glag-66, both of which are papillary thyroid carcinoma cell lines (29). TT and MZ-CRC cells were cultured in Dulbecco's modified Eagle's medium (DMEM)/F12 (Cellgro; Corning) supplemented with $15 \%$ heat inactivated fetal bovine serum (FBS; Sigma-Aldrich, Merck KGaA). NThy-ori 3-1 and K1 cell lines were cultured in RPMI-1640 and Ham's F12 medium (Thermo Fisher Scientific) supplemented with 9\% FBS, respectively. The isogenic cell line 293-RET, which has a luciferase reporter gene under the control of a wild-type RET promoter, was generated as described in a previous study conducted by the present authors (30). The 293-RET cell line was cultured in DMEM supplemented with 9\% FBS. TPC1 cells were kindly provided by Dr Rebecca Schweppe (University of Colorado Denver) and were cultured in RPMI-1640 medium supplemented with 9\% FBS. All cell lines were maintained in a humidified atmosphere containing $5 \% \mathrm{CO}_{2}$ at $37^{\circ} \mathrm{C}$. These cell lines were also tested for mycoplasma contamination and were further authenticated using STR profiling.

Cell-based screening using a luciferase assay. The 293-RET cells were plated in a 96-well plate at a concentration of $1.5 \times 10^{4}$ cells/well. The next day, the cells were treated with various concentrations $(0-3.125 \mu \mathrm{g} / \mathrm{ml})$ of salinomycin and incubated for $24 \mathrm{~h}$. Cells were then lysed with $25 \mu \mathrm{l}$ passive lysis buffer (Promega Corporation), and luciferase expression was determined using the Steady-Glo Luciferase assay system (Promega Corporation) following the manufacturer's instructions. Luciferase activity in whole cell lysates was measured in relative luminescence units and normalized to the total amount of protein.

Semi-quantitative reverse transcription $(R T)-P C R$ analysis of RET mRNA synthesis in TT cells. The mRNA expression of TT cells following exposure to increasing concentrations of salinomycin $(0.25-1 \mu \mathrm{g} / \mathrm{ml})$ was determined by RT-PCR as described previously (30). Total RNA was extracted from the cells utilizing the RNeasy Mini QIAcube kit (Qiagen, Inc.) as per the manufacturer's instructions. The extracted RNA was subjected to RT using oligo (dT)18 primer with a QuantiTect reverse transcription kit (Qiagen, Inc.) to obtain cDNA (30). The primers used for RT-PCR were as follows: RET forward, 5'-GCAGCATTGTTGGGGGACA-3' and reverse, 5'-CACC GGAAGAGGAGTAGCTG-30; ribosomal protein L9 (RPL9) forward, 5' CTGAAGGGACGCACAGTTAT-3' and reverse, 5'- ACGGTAGCCAGTTCCTTTCT-3'. The PCR step involved 
initial denaturation at $95^{\circ} \mathrm{C}$ for $3 \mathrm{~min}$ followed by 33 and 23 cycles for RET and RPL9, respectively, at $95^{\circ} \mathrm{C}$ for $30 \mathrm{sec}$, $52^{\circ} \mathrm{C}$ for $30 \mathrm{sec}$ and $72^{\circ} \mathrm{C}$ for $30 \mathrm{sec}$ on a GeneAmp ${ }^{\circledR} \mathrm{PCR}$ system 9600 (PerkinElmer, Inc.). PCR products were analyzed using 1.5\% agarose gel electrophoresis. RPL9 gene was used as the reference gene. Densitometric analysis was performed using ImageJ software (version 1.51; National Institutes of Health).

Western blotting. After 24 or 48-h treatment with salinomycin or niclosamide, whole-cell extracts (TT, K1, Nthy-ori3-1 and TPC1) were prepared as described previously (30). Protein concentration was measured using Bio-Rad Protein Assay Dye Reagent (Bio-Rad Laboratories, Inc.) as previously described (31). Proteins were resolved by either 4-12 or $12 \%$ (for proteins $<40 \mathrm{kDa}$ such as cyclin D, BCL2 and CDK4) gradient polyacrylamide SDS-PAGE, as described previously $(30,32)$. For cytosolic protein, protein fractionation was conducted using NE-PER Nuclear and Cytoplasmic Extraction Reagents (Pierce; Thermo Fisher Scientific, Inc.) according to the manufacturer's protocol. The primary antibodies used were: RET (\#3220), mTOR (\#2983), phosphorylated (p)-mTOR (\#5536), retinoblastoma (Rb; \#9309), p-Rb (\#8516S), E2F (\#3742S), p-LRP6 (\#2568), LRP6 (\#2560), p-Akt (\#9271) and Akt (\#9272) (dilution 1:1000) purchased from Cell Signaling Technology, Inc.; cyclin D (sc-20044), CDK4 (sc-260), BCL-2 (sc-509), P53 (sc-393031), P21 (sc-71811), $\beta$-catenin (sc-7963), cyclin B (sc-166152), Lamin A/C (sc-7293), GAPDH (sc-47724) and $\beta$-actin (sc-47778) (dilution 1:300) purchased from Santa Cruz Biotechnology, Inc. Mouse or rabbit IgG antibodies tagged with horseradish peroxidase (\#1706516 and \#1706515; Bio-Rad Laboratories, Inc.) were used as secondary antibodies (dilution 1:1,000). An enhanced chemiluminescence substrate kit (\#32106; Thermo Fisher Scientific, Inc.) was used for detection. Densitometric analysis was performed using ImageJ software (version 1.51). GAPDH and Lamin A/C served as a cytoplasmic and nucleus markers, respectively (32).

$N$-acetyl-L-cysteine (NAC) pretreatment. TT cells were pretreated with $1 \mathrm{mM}$ NAC (Sigma-Aldrich, Merck KGaA) for $2 \mathrm{~h}$ followed by the addition of salinomycin $(1 \mu \mathrm{g} / \mathrm{ml})$ for 24 and 48 h. Cell extracts were prepared, and protein expression was analyzed by western blotting.

Cell viability assay. TT, K1, Nthy-ori 3-1 and TPC1 cells were plated at 7,500 cells/well in a 96-well dish and incubated overnight, followed by treatment with salinomycin or salinomycin analogs at a wide range of concentrations for $96 \mathrm{~h}$. Cell viability was determined using $0.33 \mathrm{mg} / \mathrm{ml}$ MTS dye in the presence of $25 \mu \mathrm{M}$ phenazine methosulfate (PMS) as described previously (15). The absorbance was measured at $590 \mathrm{~nm}$ using a Synergy ${ }^{\mathrm{TM}}$ HT Multi-detection Microplate Reader (BioTek Instruments, Inc.).

Caspase-3 assay. TT cells were treated with different concentrations of salinomycin for $48 \mathrm{~h}$ and caspase- 3 activity was measured using the ApoAlert Caspase Fluorescent assay kit (Clonetech Laboratories, Inc.) according to the manufacturer's protocol.
Flow cytometry. Cell cycle progression was analyzed in TT cells treated with increasing concentrations of salinomycin for $48 \mathrm{~h}$, as described in a previous study conducted by the present authors (33). In brief, cells were fixed with ethanol and stained with propidium iodine (PI) before analysis by fluorescence-activated cell sorting (FACS) using a FACSCanto II instrument (BD Biosciences). Data were analyzed using BD FACSDiva v8.0.1 software (BD Biosciences).

RET RNA silencing. An siRNA sequence targeting human RET siRNA (S11935), Silencer Select Negative Control siRNA (cat. no. 4390843) and Opti-MEM Reduced Serum Medium were purchased from Thermo Fisher Scientific, Inc. In 6-well plates, cells $\left(0.25-1 \times 10^{6}\right)$ were transfected with $9 \mu 1$ Lipofectamine RNAiMAX (cat. no. 13778150; Thermo Fisher Scientific, Inc.) and 30 pmol RET siRNA in reduced serum medium as per the manufacturer's protocol. Control cells were transfected with the negative control siRNA that has no significant effect on cell proliferation and viability (data not shown). After 72 h, cells were harvested for western blot analyses.

Statistical analysis. All data are presented as the mean \pm SEM of at least three independent experiments. One-way ANOVA with Tukey's post hoc test or two-way ANOVA with Bonferroni post hoc analysis were used to test for significant differences among multiple treatment groups. A Student's t-test was performed where applicable to test the significant difference between two treatment groups. Difference between groups were considered to be statistically significant when $\mathrm{P}<0.05$. GraphPad Prism (version 5.04; GraphPad Software, Inc.) software was utilized for all data analysis.

\section{Results}

Salinomycin reduces endogenous RET expression and interferes with RET downstream signaling in MTC cells. The effect of salinomycin on RET gene transcription was examined by a luciferase reporter assay using 293-RET cells as described in a previous study by the current authors (30). This reporter cell line was constructed by stably transfecting the luciferase reporter gene under the control of the RET wild-type promoter into 293 cells (30). As shown in Fig. 1A, treatment of 293-RET cells with various concentrations of salinomycin for $24 \mathrm{~h}$ led to a significant reduction in basal luciferase expression. Next, the inhibitory effect of salinomycin on endogenous RET expression was verified using two representative MTC cell lines, TT and MZ-CRC1, which harbor C634W and M918T RET mutations, respectively (34). As shown in Fig. 1B (top panel), salinomycin decreased RET protein levels in a time- and concentration-dependent manner in TT cells. The 24-h treatment of TT cells with $0.25,0.5$ and $1 \mu \mathrm{g} / \mathrm{ml}$ of salinomycin decreased RET protein levels by 70 , 80 and $83 \%$, respectively, compared with the vehicle control. The difference in RET protein expression was significant between the various treatment groups, with the exception of 0.5 and $1 \mu \mathrm{g} / \mathrm{ml}$, which did not differ significantly (top panel; Fig. 1B). The downregulation of RET protein appeared to be more pronounced in TT cells treated with salinomycin for $48 \mathrm{~h}$ compared with those treated for $24 \mathrm{~h}$. The difference in RET protein expression was statistically significant between 

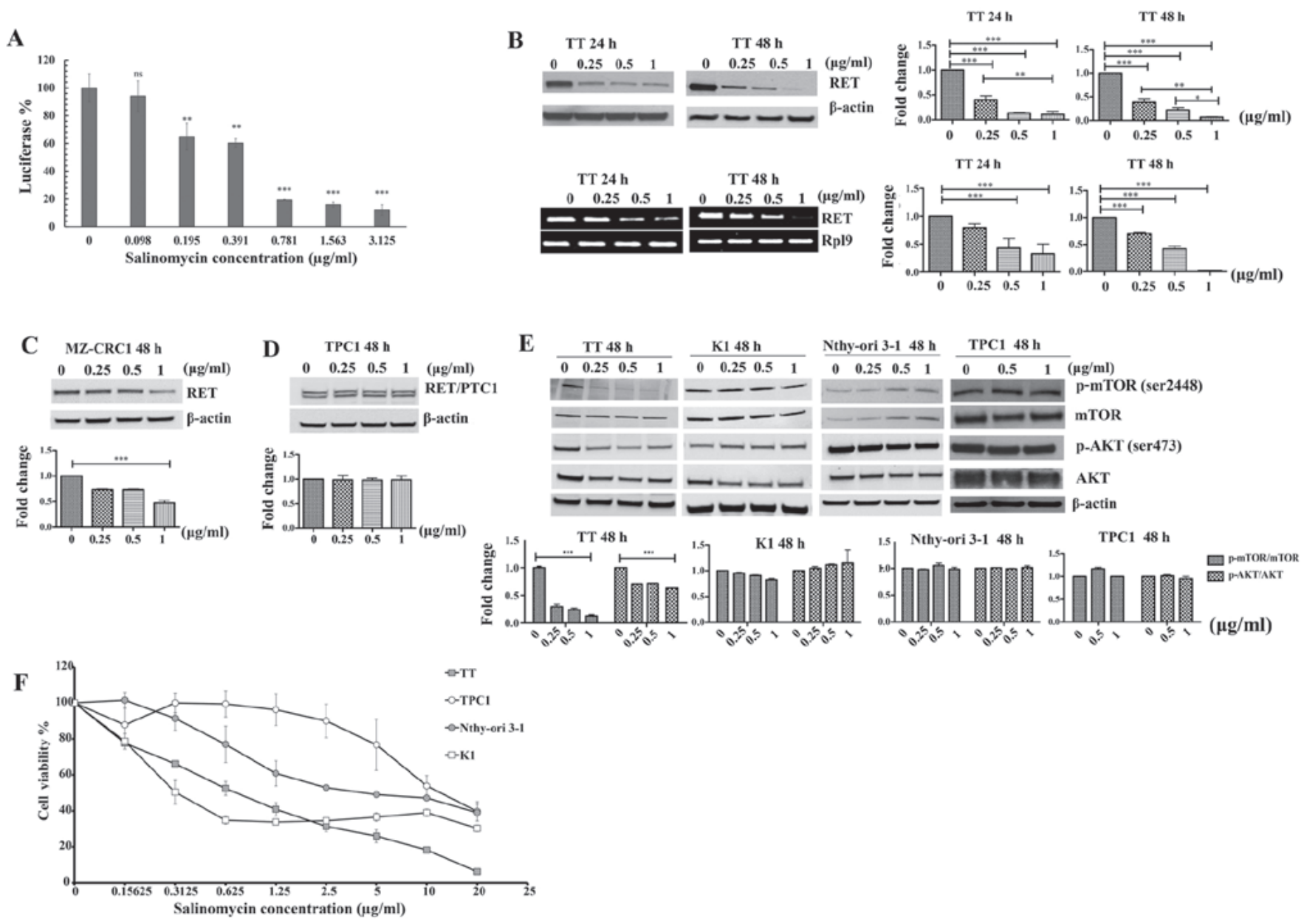

Figure 1. Effect of salinomycin on RET expression and its downstream pathways. (A) Luciferase expression in 293-RET cells after treatment with various concentrations of salinomycin for $24 \mathrm{~h}$. Luciferase activity in whole cell lysates was measured in relative luminescence units and normalized to total protein content. The $\mathrm{x}$ - and $\mathrm{y}$-axes represent the concentration of salinomycin and relative luciferase activity in the 293-RET cell line, respectively. Data were analyzed using one-way ANOVA with Tukey's post hoc test $\left(\mathrm{n}=3 ;{ }^{* *} \mathrm{P}<0.01,{ }^{* * *} \mathrm{P}<0.001\right)$. (B) Effect of salinomycin on RET protein expression (top panel) and mRNA expression (bottom panel) in TT cells after treatment with various concentrations of salinomycin for 24 and $48 \mathrm{~h}\left(\mathrm{n}=3\right.$; ${ }^{*} \mathrm{P}<0.05$, ${ }^{* *} \mathrm{P}<0.01$ and ${ }^{* * *} \mathrm{P}<0.001$ ) (C and D) Effect of salinomycin on RET protein expression in (C) MZ-CRC1 and (D) TPC1 cells, respectively, after treatment with various concentrations of salinomycin for $48 \mathrm{~h}$. The western blotting results for RET were determined by densitometric analysis with normalization to basal expression, and differences among groups were analyzed using one-way ANOVA with Tukey's post hoc test $\left(\mathrm{n}=3 ;{ }^{* * *} \mathrm{P}<0.001\right)$. (E) Cellular effects mediated by RET downregulation after treatment with salinomycin. TT, K1, Nthy-ori 3-1 and TPC1 cells were treated with salinomycin for 48-h treatment at various concentrations, and the levels of phosphorylated and total mTOR and AKT proteins were measured by western blotting. The western blotting results for p-mTOR/total mTOR and p-AKT/total AKT were determined by densitometric analysis with normalization to basal expression, and differences among groups were analyzed using one-way ANOVA with Tukey's post hoc test $\left(\mathrm{n}=3 ;{ }^{* * *} \mathrm{P}<0.001\right)$. (F) Effect of salinomycin on the proliferation of TT, K1, TPC1 and Nthy-ori 3-1 cells. Cell growth was assessed by MTS assay following treatment with various concentrations of salinomycin $(\leq 20 \mu \mathrm{g} / \mathrm{ml})$ for $96 \mathrm{~h}$. Data are the mean \pm SEM of three separate experiments RET, rearranged during transfection kinase; PTC, papillary thyroid carcinoma; p, phosphorylated; ns, not significant.

each treatment group after incubation with salinomycin for $48 \mathrm{~h}$ (top panel; Fig. 1B). To determine if the expression levels of RET protein were consistent with those of RET mRNA in TT cells treated with salinomycin, the levels of RET mRNA in TT cells treated with salinomycin were measured using RT-PCR as previously described (30). As shown in Fig. 1B (lower panel), salinomycin diminished RET mRNA expression in a time- and concentration-dependent manner, suggesting that RET protein expression corresponds with RET mRNA expression in TT cells. The RPL9 gene was used as a loading control in the present RT-PCR analysis (35). The lack of evaluation of the RET mRNA levels by RT-quantitative PCR in the present study may limit the accuracy of RET mRNA quantification in the TT cells. The effect of salinomycin on RET protein expression in MZ-CRC1 cells was also tested, following treatment with various concentrations of salinomycin for $48 \mathrm{~h}$. As shown in Fig. 1C, the treatment of MZ-CRC1 cells with salinomycin reduced RET expression compared with that in the untreated control, although to a lesser extent than in TT cells.

The effect of salinomycin on the expression of the RET fusion proteins (RET/PTC1) was investigated using a PTC cell line, TPC1, containing a fused RET/PTC1 gene. The fused $\mathrm{RET} / \mathrm{PTC1}$ protein in the TPC1 cells is formed by a chromosomal rearrangement between the RET tyrosine kinase domain coding region and the 5'-terminal region of the coiled-coil domain containing gene 6 (CCD6) at chromosom 10q11.2. This chromosomal inversion causes the transcription of the RET/PTC1 gene to be regulated by the CCD6 gene promoter region $(36,37)$. As shown in Fig. 1D, salinomycin exhibited no effect on fused RET/PTC1 expression in TPC1 cells. This result indicates that the wild-type RET promoter is required 

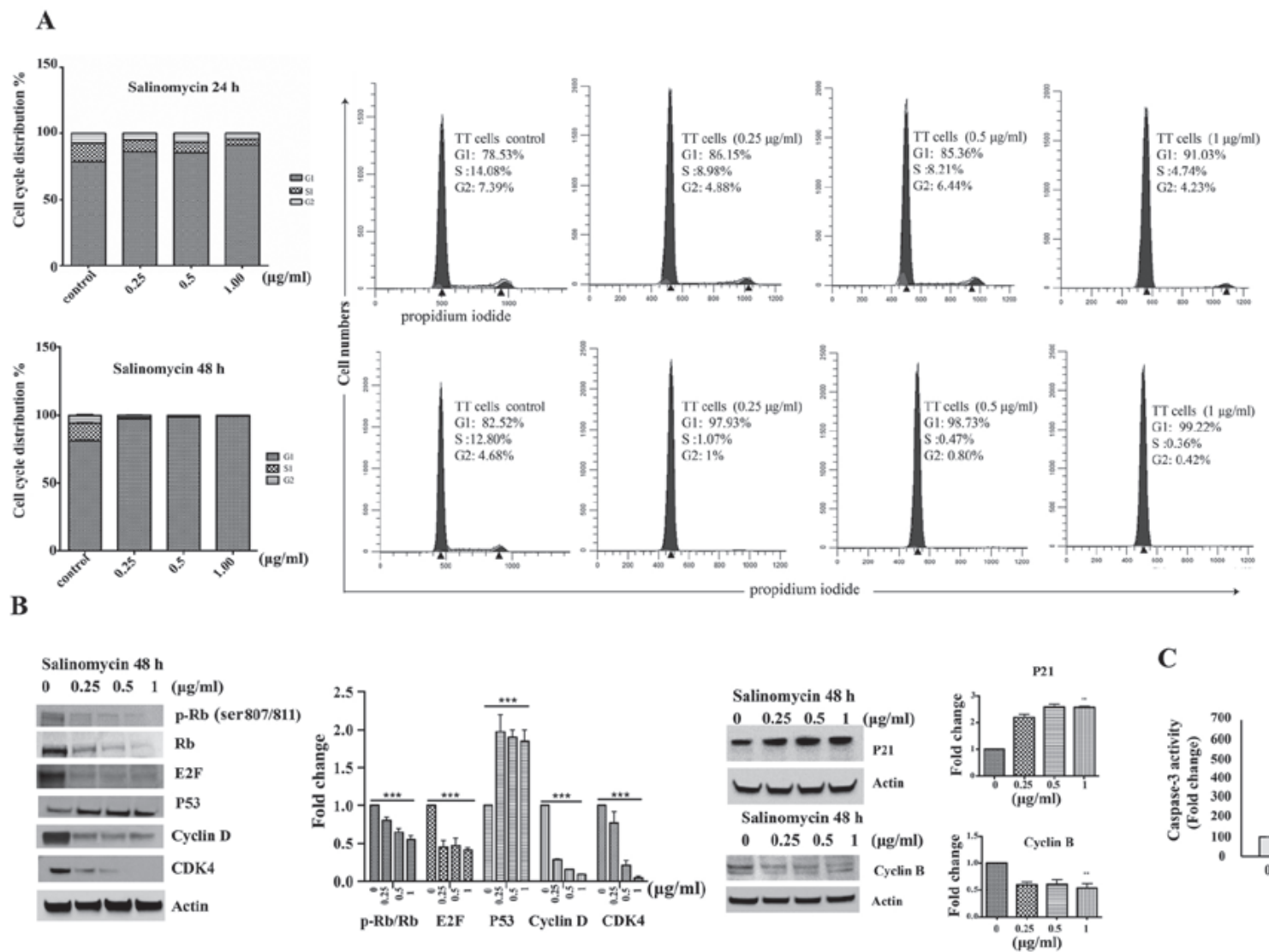

C

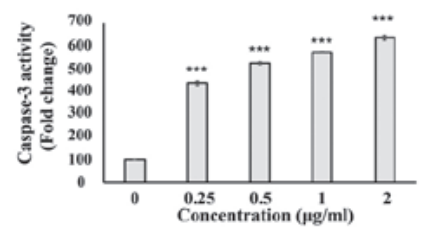

Figure 2. Effects of salinomycin on molecular events of cell cycle and apoptosis in TT cells. (A) Graphical representation of the cell cycle phase distribution of TT cell after treatment with salinomycin for 24 and $48 \mathrm{~h}$. Representative histograms of the cell cycle are shown to the right of the graphs. (B) Expression analysis of core cell cycle regulators. TT cells were treated with different concentrations of salinomycin for $48 \mathrm{~h}$ and selected cell cycle proteins, namely p-Rb, $\mathrm{Rb}, \mathrm{E} 2 \mathrm{~F}, \mathrm{P} 53$, cyclin D and CDK4 were measured by western blotting. The expression levels of P21 and cyclin B were also measured by western blotting after the treatment of TT cells with different concentrations of salinomycin $48 \mathrm{~h}$ (right side). The western blotting results were quantified by densitometric analysis with normalization to basal expression, and differences among groups were analyzed using one-way ANOVA with Tukey's post hoc test $\left(\mathrm{n}=3\right.$; ${ }^{* *} \mathrm{P}<0.005$ and $\left.{ }^{* * * *} \mathrm{P}<0.001\right)$. (C) Caspase-3 activity was determined in TT cells after treatment with salinomycin for $48 \mathrm{~h}$, as a marker of apoptosis. Data are the mean \pm SEM of three separate experiments and analyzed by one-way ANOVA with Tukey's post hoc test $\left(\mathrm{n}=3 ;{ }^{* * *} \mathrm{P}<0.001\right)$.

for the repression of RET transcription in thyroid cancer cell lines.

The PI3K/AKT/mTOR pathway has been reported to play a critical role in the tumorigenesis induced by RET oncogenes $(38,39)$. Therefore, the present study examined the effect of salinomycin on RET downstream signaling pathway in TT cells by monitoring the changes in the levels of the phosphorylated forms of AKT and mTOR relative to those of the respective total proteins. As shown in Fig. 1E, a decrease in the RET protein level in TT cells was closely associated with a reduction in the phosphorylation of AKT and mTOR, with only a slight effect on the amount of total AKT and no effect on the amount of total mTOR. However, salinomycin showed no effect on the AKT/mTOR pathway in RET-independent thyroid cells, namely K1, Nthy-ori 3-1 and TPC1, suggesting that the effect of salinomycin on the AKT/mTOR pathway is closely associated with its RET downregulatory effect.

Since activating point mutations in the RET proto-oncogene are well-documented contributors to the progression of hereditary and sporadic forms of MTC, a cell viability assay of TT, K1, Nthy-ori 3-1 and TPC1 cells was performed. On the basis of the cell viability results in Fig. 1F, the half maximal inhibitory concentration $\left(\mathrm{IC}_{50}\right)$ values of salinomycin in $\mathrm{TT}$ and $\mathrm{K} 1$ cells were estimated to be 0.3 and $0.6 \mu \mathrm{g} / \mathrm{ml}$, respectively. Notably, Nthy-ori 3-1 and TPC1 cells were less sensitive to salinomycin, with $\mathrm{IC}_{50}$ values of 4 and $15 \mu \mathrm{g} / \mathrm{ml}$, respectively, suggesting that the inhibitory effect of salinomycin against RET expression could be closely associated with its anti-proliferative effects on human thyroid cell lines.

Salinomycin induces $G 1$ cell cycle arrest and release of caspase-3. The effect of salinomycin on cell cycle progression was examined by treating TT cells with salinomycin at various concentrations for 24 and $48 \mathrm{~h}$. As shown in Fig. 2A, at $24 \mathrm{~h}$ after treatment with the highest concentration $(1 \mu \mathrm{g} / \mathrm{ml})$ of salinomycin, there was a $12-15 \%$ increase in the proportion of cells in the G1 phase compared with the control. Treatment with $1 \mu \mathrm{g} / \mathrm{ml}$ salinomycin for $48 \mathrm{~h}$ resulted in a greater increase in the proportion of cells in the G1 phase, by $16-20 \%$ compared with the non-treated cells, which was accompanied by a reduction in the number of cells in the S and G2 phases. To confirm the cell cycle arrest, the expression levels of core cell cycle regulatory proteins (cyclin D, CDK4, P53, E2F, p-Rb and $\mathrm{Rb}$ ) were assessed in TT cells following treatment with salinomycin for $48 \mathrm{~h}$. As shown in Fig. 2B, western blotting revealed a strong downregulation of the expression of cyclin D, CDK4 

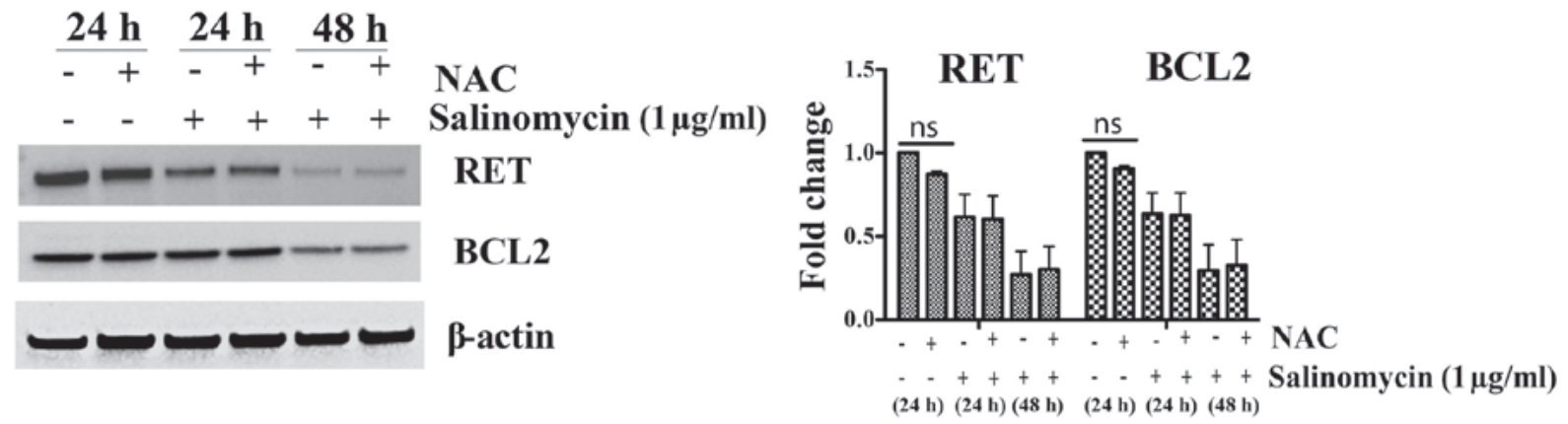

Figure 3. Effects of NAC on salinomycin-mediated RET downregulation and BCL2 in TT cells. TT cells were treated with salinomycin for 24 or $48 \mathrm{~h}$ with or without NAC (1 mM). Expression levels of RET and BCL2 were determined by western blotting. The western blotting results for RET and BCL2 were quantified by densitometric analysis with normalization to basal expression, and differences among groups were analyzed using two-way ANOVA with Bonferroni post hoc test $(n=3)$. NAC, $\mathrm{N}$-acetyl cysteine; RET, rearranged during transfection kinase; ns, not significant.

and E2F. Furthermore, salinomycin decreased $\mathrm{p}-\mathrm{Rb}$ and total $\mathrm{Rb}$ levels compared with the respective baseline levels, and resulted in a significant increase in P53 expression. P21 and cyclin B proteins were evaluated in TT cells after treatment with salinomycin for 48 h. P21 was upregulated while cyclin B was downregulated after the 48-h treatment (Fig. 2B).

Whether salinomycin can induce apoptosis was determined by measuring the activity of caspase- 3 , since caspase- 3 activation is an apoptotic event that precedes cell death (40). As shown in Fig. 2C, caspase-3 activity in salinomycin-treated cells was significantly increased in a concentration-dependent manner compared with the control after $48 \mathrm{~h}$ of treatment, which indicates the apoptosis-inducing effect of salinomycin on TT cells.

RET downregulation in TT cells after salinomycin treatment is independent of ROS activation. Oxidative stress can dictate the fate of cells. At high levels, ROS can induce cytotoxic or cytostatic effects, whereas at low levels, they can facilitate cell differentiation and proliferation (41). As has been documented in previous studies, numerous anticancer drugs induce programmed cell death, in whole or in part, by generating ROS $(42,43)$. To assess whether ROS production is associated with the effect of salinomycin on RET expression or apoptosis, TT cells were pre-treated with the ROS scavenger N-acetyl cysteine (NAC). As shown in Fig. 3, after treatment with $1 \mu \mathrm{g} / \mathrm{ml}$ salinomycin for 24 and $48 \mathrm{~h}$, RET and BCL2 protein expression levels were not changed by NAC pre-treatment, suggesting that RET suppression by salinomycin is independent of ROS induction in the MTC model.

Salinomycin analogs show varying effects compared with the parent compound on RET expression. To investigate the structure-activity relationship of salinomycin, analogs of salinomycin generated by chemical synthesis as described in a previous study, including salinomycin amide (A1-A8) and ester (E1-E8) derivatives were used $(7,8)$. Salinomycin analogs have previously been evaluated for cytotoxicity and selectivity against TT, K1, Nthy-Ori 3-1 and TPC1 cell lines (Fig. 4A) $(28,44)$. As shown Fig. 4A, the majority of the derivatives possessed considerably less potent cytotoxic effects against normal and cancer thyroid cell lines than did salinomycin. However, A3 and E4 exhibited more potent cytotoxicity against these cell lines than the parent compound, with $\mathrm{IC}_{50}$ values in the ranges of $0.5-2.2$ and $0.07-0.8 \mu \mathrm{g} / \mathrm{ml}$, respectively. It is also worthwhile to note that A3 and E4 exhibited relatively selective cytotoxicity to TT and K1 cells over TPC1 and the normal immortalized thyroid cells, Nthy-ori 3-1. Next, the effects of selected salinomycin analogs on endogenous RET expression were examined in TT cells to determine if the structure-related cytotoxic effects of salinomycin analogs are associated with their potential to downregulate the expression of RET protein. As shown in Fig. 4B, nontoxic amide (A2 and A4) and ester (E1) derivatives showed no effect on RET expression in TT cells after 48-h treatment with $\leq 10$ and $5 \mu \mathrm{g} / \mathrm{ml}$ of the analogs, respectively. However, the most potent ester derivative, E4, effectively reduced RET expression in TT after $48 \mathrm{~h}$ of treatment at a concentration of $0.6 \mu \mathrm{g} / \mathrm{ml}$. The extent of the reduction in RET expression achieved with salinomycin E4 is comparable to that of salinomycin. These results suggest that the cytotoxic effects of salinomycin derivatives are closely associated with their downregulatory effect on RET expression in TT cells.

RET reduction can lead to LRP6 attenuation in MTC cell lines. Previous studies demonstrated that RET is a novel transcriptional target of Wnt/ $\beta$-catenin signaling $(19,45)$. Since salinomycin is known to interfere with Wnt signaling, whether the RET downregulatory effect of salinomycin is mediated through its inhibitory effect on $\mathrm{Wnt} / \beta$-catenin pathway was examined in TT cells in the present study (46). As shown in Fig. 5A, salinomycin induced a significant reduction in total, cytosolic and nuclear $\beta$-catenin, p-LRP6 and total LRP6 in TT cells after $48 \mathrm{~h}$ of treatment. To further verify the involvement of the Wnt pathway in the RET-inhibitory effect of salinomycin, the well-characterized Wnt inhibitor niclosamide , was used as a positive control in the present study $(47,48)$. Notably, niclosamide was able to reduce p-LRP6, LRP6 and total $\beta$-catenin, as well as RET expression in TT and MZ-CRC1 cells (Fig. 5B). These results suggest the existence of a close relationship between the Wnt/ $\beta$-catenin and RET pathways in MTC, in agreement with previous studies $(27,45)$. Whether the activity of the Wnt/ $\beta$-catenin pathway is associated with activation of RET pathway was also investigated in the present study. Therefore, TT cells were transfected with RET siRNA or negative control siRNA for $72 \mathrm{~h}$. As shown in 
A

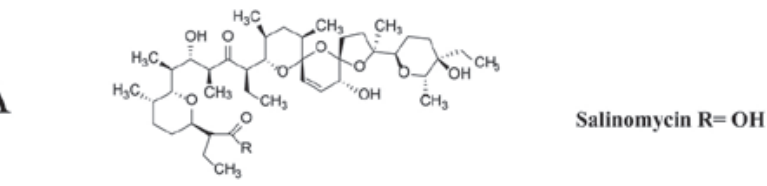

\begin{tabular}{|c|c|c|c|c|c|c|c|c|c|c|c|}
\hline \multirow[b]{2}{*}{ Compound } & \multirow[b]{2}{*}{$\mathbf{R}=$} & \multicolumn{4}{|c|}{$\mathrm{IC}_{\mathrm{se}} \pm \mathrm{SD}(\mu \mathrm{g} / \mathrm{ml})$} & \multirow[b]{2}{*}{ Compound } & \multirow[b]{2}{*}{$\mathbf{R}=$} & \multicolumn{4}{|c|}{$\mathrm{IC}_{50} \pm \mathrm{SD}(\mu \mathrm{g} / \mathrm{ml})$} \\
\hline & & TT & K1 & Nthy-ori 3-1 & TPC1 & & & TT & K1 & Nthy-ori 3-1 & TPC1 \\
\hline A1 & $H^{\prime} \equiv$ & $>20 \pm 1.40$ & $15 \pm 1.75$ & $>20 \pm 0.7$ & $>20 \pm 0.40$ & E1 & $0^{\wedge}=$ & $11 \pm 0.50$ & $10 \pm 0.80$ & $14.9 \pm 1.25$ & $12.6 \pm 2.40$ \\
\hline$A 2$ & & $>20 \pm 1.90$ & $>20 \pm 2.40$ & $>20 \pm 1.10$ & $>20 \pm 0.3$ & E2 & & $>20 \pm 0.50$ & $19.5 \pm 3.55$ & $17.5 \pm 3.55$ & $>20 \pm 1.10$ \\
\hline A3 & r & $0.5 \pm 0.2$ & $1 \pm 0.07$ & $2.0 \pm 0.3$ & $2.2 \pm 0.3$ & E3 & & $>20 \pm 0.60$ & $>20 \pm 0.7$ & $>20 \pm 0.3$ & $>20 \pm 3.1$ \\
\hline A4 & & $>20 \pm 1.90$ & $>20 \pm 0.1$ & $>20 \pm 0.9$ & $>20 \pm 0.3$ & E4 & & $0.07 \pm 0.01$ & $0.1 \pm 0.10$ & $0.2 \pm 0.37$ & $0.8 \pm 0.3$ \\
\hline A5 & & $>\mathbf{2 0} \pm \mathbf{0 . 7 0}$ & $>20 \pm 1.1$ & $>20 \pm 0.7$ & $>20 \pm 4.40$ & E5 & & $>20 \pm 1.90$ & $>20 \pm 0.9$ & $>20 \pm 0.3$ & $>20 \pm 0.81$ \\
\hline A6 & & $7.1 \pm 1.90$ & $13 \pm 1.01$ & $8.1 \pm 3.7$ & $8.5 \pm 0.3$ & E6 & & $10.5 \pm 1.05$ & $5 \pm 0.80$ & $13.5 \pm 2.35$ & $8.7 \pm 2.80$ \\
\hline A7 & & $>20 \pm 1.90$ & $15 \pm 1.2$ & $10 \pm 3.7$ & $10 \pm 0.3$ & E7 & & $>20 \pm 1.07$ & $7.5 \pm 1.00$ & $>20 \pm 1.23$ & $>20 \pm 0.41$ \\
\hline A8 & & $>20 \pm 0.40$ & $>20 \pm 0.9$ & $>20 \pm 1.87$ & $>20 \pm 0.10$ & E8 & & $>20 \pm 2.40$ & $>20 \pm 1.7$ & $>20 \pm 0.3$ & $>20 \pm 3.80$ \\
\hline
\end{tabular}

$\mathrm{B}$
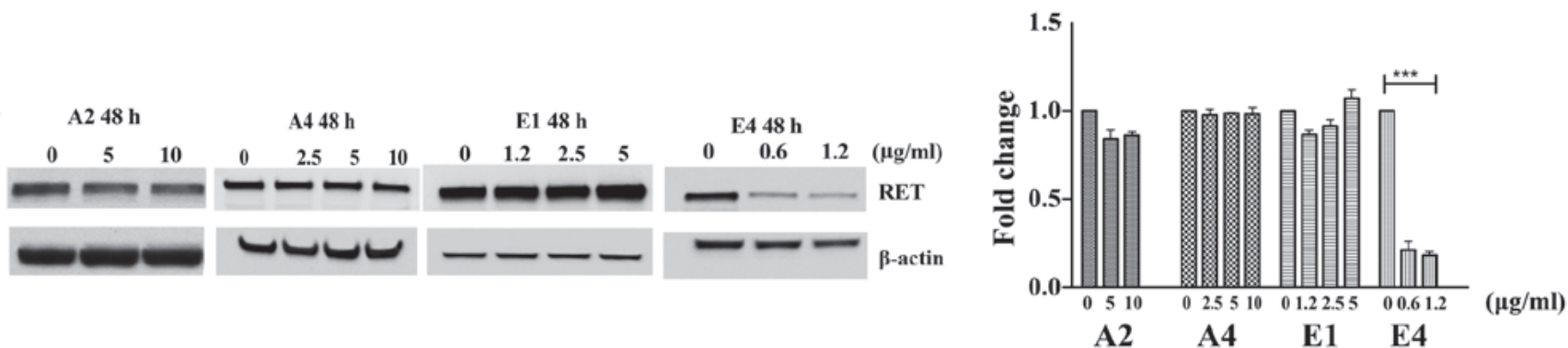

Figure 4. Effect of salinomycin amide ('A') and ester ('E') derivatives on the proliferation of TT, K1, Nthy-ori 3-1 and TPC1 cells, and the effect of selected salinomycin derivatives on RET protein expression in TT cells $(28,44)$. (A) TT, K1, TPC1 and Nthy-ori 3-1 cells were treated with an increasing concentration of each derivative for $96 \mathrm{~h}$. The $\mathrm{IC}_{50}$ value of each compound was determined by MTS assay. Data are mean \pm SEM of three separate experiments. (B) Effect of selected salinomycin analogs on RET protein expression in TT cells was determined by western blotting after treatment for $48 \mathrm{~h}$. Densitometric analysis of the western blotting results for RET was conducted with normalization to basal expression, and differences among groups were analyzed using one-way ANOVA with Tukey's post hoc test $\left(\mathrm{n}=3 ;{ }^{* * * *} \mathrm{P}<0.001\right)$. $\mathrm{IC}_{50}$, half maximal inhibitory concentration; RET, rearranged during transfection kinase.

Fig. 5C, RET was successfully knocked down by RET siRNA transfection compared with the negative control siRNA. Total LRP6 expression was also reduced by RET siRNA compared with the negative control (Fig. 5C), indicating the likelihood of crosstalk between RET and the LRP6 (Wnt) pathway in TT cells. Furthermore, RET and LRP6 levels declined concurrently in TT cells following treatment with $1 \mu \mathrm{g} / \mathrm{ml}$ salinomycin at different time points (Fig. 5D). The effects of various salinomycin analogs on the expression levels of LRP6 and p-RLP6 in TT cells were also examined. As shown in Fig. 5E, there appears to be a strong association between the ability of an analog to reduce the expression of RET and its ability to reduce p-LRP6 and LRP6 expression. Analogs such as A2, A4 and E1, which were not able to reduce RET expression (Fig. 4B) were also unable to alter RLP6 expression or phosphorylation (Fig. 5E), while derivatives that were able to reduce RET expression, such as E4, were also able to reduce the expression and phosphorylation of LRP6.

\section{Discussion}

Due to the major contribution of germline mutations in the RET proto-oncogene to the development of MTC, activated RET protein is considered to be a weakness of MTC $(38,49)$. Previous studies have developed several therapeutic strategies against RET-driven MTC $(11,21,50)$. These include the use of tyrosine 
A

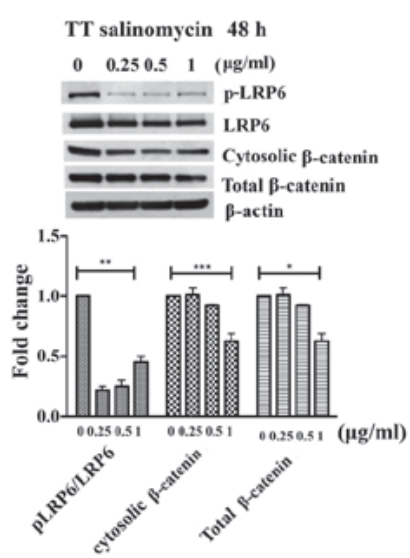

C
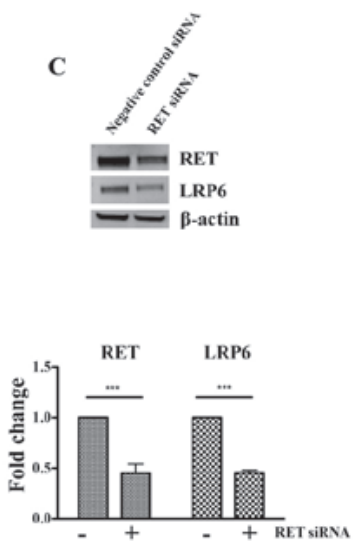

TT salinomycin 48 h

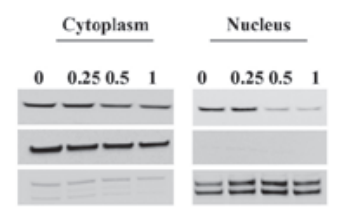

$\mu \mathrm{g} / \mathrm{ml}$

B-eatenin

GAPDH

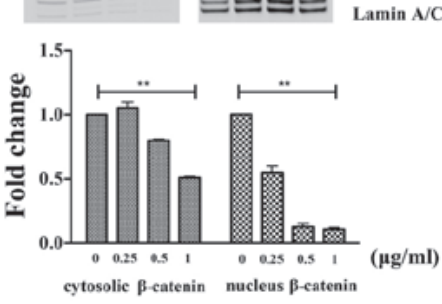

Salinomycin $1 \mu \mathrm{g} / \mathrm{ml}$
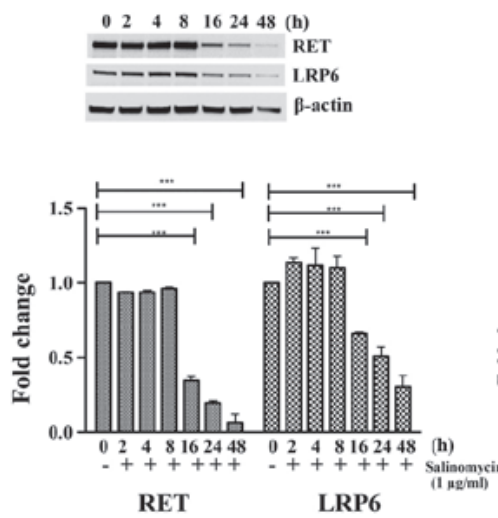

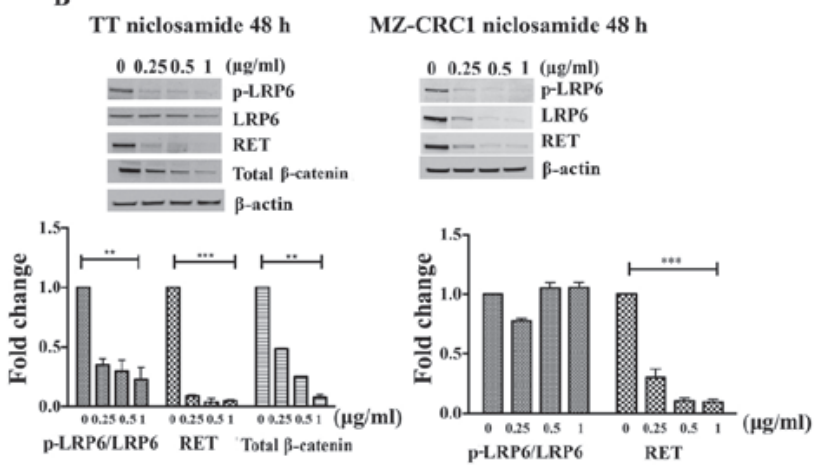

E

E4

0 0.61 .22 .5

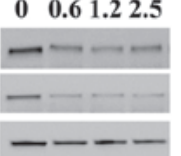

A4

$\underline{\mathrm{A} 2}$

E1

$\begin{array}{lllllllllll}0 & 2.5 & 5 & 10 & 0 & 2.5 & 5 & 0 & 1.2 & 2.5 & 5\end{array}$

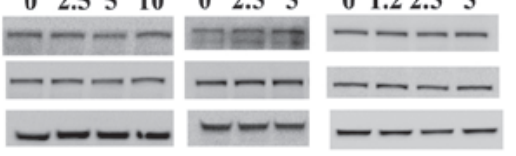

p-LRP6

LRP6

$\beta$-actin

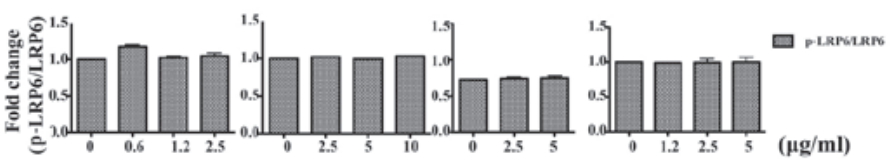

Figure 5. Effect of salinomycin on Wnt/ $\beta$-catenin signaling and crosstalk between RET and LRP6. (A) Expression levels of p-LRP6, LRP6, cytosolic $\beta$-catenin and total $\beta$-catenin were determined by western blotting in TT cells after treatment with salinomycin for $48 \mathrm{~h}$. The expression levels of cytosolic and nuclear $\beta$-catenin were also measured. Proteins expression were determined by densitometric analysis with normalization to basal expression, and differences among groups were analyzed using one-way ANOVA with Tukey's post hoc test $\left(\mathrm{n}=3 ;{ }^{*} \mathrm{P}<0.05,{ }^{* *} \mathrm{P}<0.01\right.$ and $\left.{ }^{* * *} \mathrm{P}<0.001\right)$. (B) Effect of niclosamide on the levels of p-LRP6, LRP6 and RET in TT and MZ-CRC1 cells, and total $\beta$-catenin in TT cells were determined by western blotting. The western blotting results for the shown proteins were determined by densitometric analysis with normalization to basal expression, and differences among groups were analyzed using one-way ANOVA with Tukey's post hoc test $\left(\mathrm{n}=3 ;{ }^{* *} \mathrm{P}<0.01\right.$ and $\left.{ }^{* * *} \mathrm{P}<0.001\right)$. (C) Western blot analysis of the expression of LRP6 and RET in RET siRNA and silencer negative control-treated TT cells. Representative images are shown, with normalized densitometric quantification and analysis of the difference between groups by Student's t-test $\left(\mathrm{n}=3\right.$; $\left.{ }^{* * *} \mathrm{P}<0.001\right)$. (D) Time course of the expression of RET and LRP6 protein in TT cells in the presence of $1 \mu \mathrm{g} / \mathrm{ml}$ salinomycin $\left(\mathrm{n}=3 ;{ }^{* * *} \mathrm{P}<0.001\right)$. (E) Effect of salinomycin analogs (E4, A4, A2 and E1) on the p-LRP6/LRP6 ratio in TT cells after treatment for $\leq 48 \mathrm{~h}$. Western blotting results for all proteins were determined by densitometric analysis with normalization to basal expression, and differences among groups were analyzed using one-way ANOVA with Tukey's post hoc test $(\mathrm{n}=3)$. LRP6, low-density lipoprotein receptor-related protein 6; $\mathrm{p}$, phosphor; RET, rearranged during transfection kinase; siRNA, small interfering RNA.

kinase inhibitors, siRNAs that silence mutant RET expression, and gene therapies that utilize dominant-negative RET to suppress downstream signaling pathways $(17,39)$. To date, two multi-target tyrosine kinase inhibitors (vandetanib and cabozantinib), which target vascular endothelial growth factor receptor 2, EGFR, MET and RET, have been approved for the treatment of locally advanced and metastatic MTC. However, long-term vandetanib or cabozantinib treatment for advanced MTC has two significant disadvantages: Efficacy is lost over time as a result of acquired drug resistance, and prolonged treatment can cause serious side effects $(20,21,51,52)$. Thus, there is an urgent need to identify and discover new therapeutic agents that are able to interfere with RET function for use in the curative therapy of MTC.

The potassium ionophore salinomycin has shown inhibitory effects on the Wnt/ $\beta$-catenin pathway in various cancer models (46). In the present study, salinomycin was shown to be a potential therapeutic agent for MTC that can target RET and its downstream signaling. The present study also demonstrated that the suppression of RET by salinomycin is closely associated with its anti-proliferative and apoptotic effects on human MTC cell lines, with a particularly strong inhibitory effect on cells with RET mutations at C634W, such as TT cells. Although MZ-CRC1 is an MTC cell line, it appears to be less sensitive than TT cells to salinomycin (Fig. 1C). It may be speculated that there are some genes that are highly overexpressed in the RET M918T mutant but not the C634W mutant that could contribute to salinomycin sensitivity in MZ-CRC1 (53). Salinomycin demonstrated no clear effect on the papillary thyroid carcinoma cell line TPC1, in which its $\mathrm{IC}_{50}$ was $>10$-fold higher than that for TT cells (Fig. 1F). Likewise, 
salinomycin showed no effect on the expression of the rearranged RET/PTC1 protein in TPC1 cells (Fig. 1D). RET/PTC1 transcription is regulated by the CCD6 gene promoter region, leading to the speculation that a wild-type RET promoter region is essential for mediation of the RET-inhibiting effect of salinomycin. Furthermore, salinomycin did not exert any detectable effect on RET downstream proteins such as p-mTOR, mTOR, p-AKT and AKT in TPCl cells (Fig. 1E). $\mathrm{K} 1$ cells, which are derived from a primary papillary thyroid carcinoma, have been found to have enhanced Wnt signaling for growth and survival with wild-type status for RET (54). Thus, the disruption of Wnt signaling could be the basis of the anti-proliferative activity of salinomycin against $\mathrm{K} 1$ cells. Therefore, at a low concentration, salinomycin appears to be selective, with a stronger anti-proliferative effect on TT and K1 cells compared with TPC1 and Nthy-ori 3-1 cells.

Cell cycle analysis by flow cytometry demonstrated that the treatment of TT cells with salinomycin for 24 or $48 \mathrm{~h}$ resulted in cell cycle arrest at the G1 phase in a concentration-dependent manner (Fig. 2A). The cell cycle is highly regulated by different types of cyclin-dependent kinases and their catalytic units; cyclin D, E2F, Rb, P53, P21, cyclin B and CDK4 serve important roles in cell cycle progression through the G1 phase $(55,56)$. After treatment of TT cells with salinomycin, the aforementioned regulators were reduced in a concentration-dependent manner (Fig. 2B). However, P27 was not evaluated in the current cell cycle analysis. The cell cycle arrest at the G1 phase was followed by increased caspase- 3 activity after $48 \mathrm{~h}$ of treatment with salinomycin. Recent reports have shown that salinomycin induces apoptosis in various human cancer cell lines, in part due to the accumulation of ROS $(57,58)$; however, pre-treatment of TT cells with the antioxidant NAC could not rescue TT cells from apoptosis, nor could it reduce the loss of BCL2 or RET (Fig. 3). This indicates that the apoptosis of TT cells after salinomycin treatment is independent of ROS activation or generation.

In the current study, the potential anticancer activities of salinomycin amide and ester derivatives are presented. Although the majority of the salinomycin derivatives were not capable of either reducing RET expression in TT cells or inducing selective cytotoxicity, salinomycin E4 produced promising results. Salinomycin E4 significantly reduced RET expression in TT cells at submicromolar concentrations and also diminished total and p-LRP6 levels. The effect on LRP6 demonstrates the importance of the Wnt $/ \beta$-catenin pathway in the mediation of the anticancer activity of salinomycin and its analogs. The Wnt/ $\beta$-catenin pathway is essential in embryonic development and thyrocyte proliferation $(23,27)$. The abnormal activation of $\mathrm{Wnt} / \beta$-catenin is associated with multiple types of cancer $(23,25)$. The Wnt pathway is activated by the binding of Wnt glycoproteins to Frizzled and its co-receptor LRP6 to form a ternary complex in the cell membrane. Phosphorylation of LRP6 leads to disruption of the $\beta$-catenin destruction complex, which includes adenomatosis polyposis coli, glycogen synthase kinase 3 , axin and casein kinase 1 . This destruction complex typically phosphorylates cytoplasmic $\beta$-catenin, and targets it for ubiquitination and proteolytic degradation in the absence of Wnt. Upon activation, Wnt/ $\beta$-catenin signaling stabilizes cytosolic $\beta$-catenin, allowing it to translocate to the nucleus and form a complex with T-cell factor/lymphoid enhancer factor. This complex activates target genes that are vital for cell growth and survival $(27,59)$. A previous study demonstrated that activation of Wnt/ $\beta$-catenin by lithium chloride upregulated RET expression in a concentration-dependent manner in mIMCD-3 cells, whereas LRP6 knockout downregulated RET expression in mouse embryos (19). In the present study, niclosamide, a specific Wnt/ $\beta$-catenin inhibitor, was demonstrated to diminish RET expression by disrupting Wnt signaling in TT cells. Also, siRNA-mediated RET knockdown led to the downregulation of LRP6 and RET expression in TT cells compared with the negative control. The cytotoxicity of salinomycin derivatives appears to be established via their ability to reduce the activity and the expression of LRP6 and RET. On the basis of the aforementioned results, it is hypothesized that LRP6-mediated Wnt/ $\beta$-catenin signaling either modulates or closely interacts with RET or RET downstream proteins in MTC, and that this crosstalk is disrupted by salinomycin, selected salinomycin analogs, niclosamide or RET siRNA.

In conclusion, the current study demonstrates that salinomycin, characterized as an inhibitor of the Wnt pathway, exerts potent antitumor activity against MTC via the reduction of RET expression. The chemical modification of salinomycin can provide derivatives with stronger cytotoxity. Niclosamide and other salinomycin derivatives, which reduce LRP6 expression, highlight the important role of the Wnt signaling pathway in the regulation of RET expression in MTC. This preliminary study reveals the effects of salinomycin and its derivatives on MTC cells in vitro. Since salinomycin has been reported to have serious side effects on the cardiovascular system, the evaluation of the toxicity of salinomycin and salinomycin derivatives as well as their efficacy in an in vivo MTC model is pivotal (60). However, the findings of the current study support further preclinical evaluation of salinomycin and its analogs as novel therapeutic agents for the treatment of MTC.

\section{Acknowledgements}

Not applicable.

\section{Funding}

The authors thank the American Cancer Society for their support of this study (grant no. RSGM-12-046-01-CDD).

\section{Availability of data and materials}

The datasets used and/or analyzed during the current study are available from the corresponding author on reasonable request.

\section{Authors' contributions}

TA, VMK and DS conceived of and designed the study; TA and DS analyzed the data, interpreted the results of the experiments and drafted the manuscript; TA, VMK and DS prepared figures, and edited and revised the manuscript; TA, AH and VMK performed the experiments. All authors read and approved the final manuscript. 


\section{Ethics approval and consent to participate}

Not applicable.

\section{Patient consent for publication}

Not applicable.

\section{Competing interests}

No conflicts of interest, financial or otherwise, are declared by the authors.

\section{References}

1. Zhou S, Wang F, Wong ET, Fonkem E, Hsieh TC, Wu JM and Wu E: Salinomycin: A novel anti-cancer agent with known anti-coccidial activities. Curr Med Chem 20: 4095-4101, 2013.

2. Zhang Y, Liu L, Li F, Wu T, Jiang H, Jiang X, Du X and Wang Y: Salinomycin exerts anticancer effects on PC-3 cells and PC-3-derived cancer stem cells in vitro and in vivo. BioMed Res Int 2017: 4101653, 2017

3. Yu Z, Cheng H, Zhu H, Cao M, Lu C, Bao S, Pan Y and Li Y: Salinomycin enhances doxorubicin sensitivity through reversing the epithelial-mesenchymal transition of cholangiocarcinoma cells by regulating ARK5. Braz J Med Biol Res 50: e6147, 2017.

4. Verdoodt B, Vogt M, Schmitz I, Liffers ST, Tannapfel A and Mirmohammadsadegh A: Salinomycin induces autophagy in colon and breast cancer cells with concomitant generation of reactive oxygen species. PLoS One 7: e44132, 2012.

5. McCarroll JA, Phillips PA, Kumar RK, Park S, Pirola RC, Wilson JS and Apte MV: Pancreatic stellate cell migration: Role of the phosphatidylinositol 3-kinase(PI3-kinase) pathway. Biochem Pharmacol 67: 1215-1225, 2004

6. Gupta PB, Onder TT, Jiang G, Tao K, Kuperwasser C, Weinberg RA and Lander ES: Identification of selective inhibitors of cancer stem cells by high-throughput screening. Cell 138: 645-659, 2009.

7. Antoszczak M, Urbaniak A, Delgado M, Maj E, Borgström B, Wietrzyk J, Huczyński A, Yuan Y, Chambers TC and Strand D: Biological activity of doubly modified salinomycin analogs Evaluation in vitro and ex vivo. Eur J Med Chem 156: 510-523, 2018

8. Urbaniak A, Delgado M, Antoszczak M, Huczyński A and Chambers TC: Salinomycin derivatives exhibit activity against primary acute lymphoblastic leukemia (ALL) cells in vitro. Biomed Pharmacother 99: 384-390, 2018.

9. Roy M, Chen H and Sippel RS: Current understanding and management of medullary thyroid cancer. Oncologist 18 : 1093-1100, 2013

10. Nozhat $\mathrm{Z}$ and Hedayati M: Medullary thyroid carcinoma: A review on ethical considerations in treatment of children. J Pediatr Endocrinol Metab 29: 633-639, 2016.

11. Priya SR, Dravid CS, Digumarti R and Dandekar M: Targeted therapy for medullary thyroid cancer: A review. Front Oncol 7: 238, 2017.

12. Wells SA Jr, Pacini F, Robinson BG and Santoro M: Multiple endocrine neoplasia type 2 and familial medullary thyroid carcinoma: An update. J Clin Endocrinol Metab 98: 3149-3164, 2013.

13. Nelkin B: Recent advances in the biology and therapy of medullary thyroid carcinoma. F1000 Res 6: 2184, 2017.

14. Roskoski R Jr and Sadeghi-Nejad A: Role of RET protein-tyrosine kinase inhibitors in the treatment RET-driven thyroid and lung cancers. Pharmacol Res 128: 1-17, 2018.

15. Moura MM, Cavaco BM, Pinto AE and Leite V: High prevalence of RAS mutations in RET-negative sporadic medullary thyroid carcinomas. J Clin Endocrinol Metab 96: E863-E868, 2011.

16. Salvatore D, Melillo RM,Monaco C, Visconti R, Fenzi G, Vecchio G, Fusco A and Santoro M: Increased in vivo phosphorylation of ret tyrosine 1062 is a potential pathogenetic mechanism of multiple endocrine neoplasia type 2B. Cancer Res 61: 1426-1431, 2001.

17. de Groot JWB, Links TP, Plukker JTM, Lips CJM and Hofstra RMW: RET as a diagnostic and therapeutic target in sporadic and hereditary endocrine tumors. Endocr Rev 27: $535-560,2006$
18. Kramer ER, Aron L, Ramakers GMJ, Seitz S, Zhuang X, Beyer K, Smidt MP and Klein R: Absence of Ret signaling in mice causes progressive and late degeneration of the nigrostriatal system. PLoS Biol 5: e39, 2007.

19. Wang Y, Stokes a., Duan Z, , Hui J, Xu Y, Chen Y, Chen HW, Lam $\mathrm{K}$ and Zhou CJ: LDL receptor-related protein 6 modulates Ret proto-oncogene signaling in renal development and cystic dysplasia. J Am Soc Nephrol 27: 417-427, 2016.

20. Elisei R, Schlumberger MJ, Müller SP, Schöffski P, Brose MS, Shah MH, Licitra L, Jarzab B, Medvedev V, Kreissl MC, et al: Cabozantinib in progressive medullary thyroid cancer. J Clin Oncol 31: 3639-3646, 2013.

21. Grabowski P, Briest F, Baum RP, Zaknun JJ, Kulkarni HR, Zeitz $\mathrm{M}$ and Hörsch D: Vandetanib therapy in medullary thyroid cancer. Drugs Today (Barc) 48: 723-733, 2012.

22. Wells SA Jr, Robinson BG, Gagel RF, Dralle H, Fagin JA, Santoro M, Baudin E, Elisei R, Jarzab B, Vasselli JR, et al: Vandetanib in patients with locally advanced or metastatic medullary thyroid cancer: A randomized, double-blind phase III trial. J Clin Oncol 30: 134-141, 2012.

23. Zhan T, Rindtorff $\mathrm{N}$ and Boutros $\mathrm{M}$ : Wnt signaling in cancer. Oncogene 36: 1461-1473, 2017.

24. Novellasdemunt L, Antas P and Li VSW: Targeting Wnt signaling in colorectal cancer. A review in the theme: Cell signaling: Proteins, pathways and mechanisms. Am J Physiol Cell Physiol 309: C511-C521, 2015.

25. Takigawa $\mathrm{Y}$ and Brown AMC: Wnt signaling in liver cancer. Curr Drug Targets 9: 1013-1024, 2008.

26. Sastre-Perona A and Santisteban P: Wnt-independent role of $\beta$-catenin in thyroid cell proliferation and differentiation. Mol Endocrinol 28: 681-695, 2014.

27. Sastre-Perona A and Santisteban P: Role of the wnt pathway in thyroid cancer. Front Endocrinol (Lausanne) 3: 31, 2012.

28. Huczyński A, Antoszczak M, Kleczewska N, Lewandowska M, Maj E, Stefańska J, Wietrzyk J, Janczak J and Celewicz L: Synthesis and biological activity of salinomycin conjugates with floxuridine. Eur J Med Chem 93: 33-41, 2015.

29. Meireles AM, Preto A, Rocha AS, Rebocho AP, Máximo V, Pereira-Castro I, Moreira S, Feijão T, Botelho T, Marques R, et al: Molecular and genotypic characterization of human thyroid follicular cell carcinoma-derived cell lines. Thyroid 17: 707-715, 2007.

30. Kumarasamy VM and Sun D: Demonstration of a potent RET transcriptional inhibitor for the treatment of medullary thyroid carcinoma based on an ellipticine derivative. Int J Oncol 51: 145-157, 2017.

31. Lauf PK, Alqahtani T, Flues K, Meller J and Adragna NC: Interaction between Na-K-ATPase and Bcl-2 proteins BclXL and Bak. Am J Physiol Cell Physiol 308: C51-C60, 2015.

32. Ando Y, Tomaru Y, Morinaga A, Burroughs AM, Kawaji H, Kubosaki A, Kimura R, Tagata M, Ino Y, Hirano H, et al: Nuclear pore complex protein mediated nuclear localization of dicer protein in human cells. PLoS One 6: e23385, 2011.

33. Shin YJ, Kumarasamy V, Camacho D and Sun D: Involvement of G-quadruplex structures in regulation of human RET gene expression by small molecules in human medullary thyroid carcinoma TT cells. Oncogene 34: 1292-1299, 2015.

34. Schweppe RE: Thyroid cancer cell line misidentification: An update. J Clin Endocrinol Metab 98: 956-957, 2013.

35. de Jonge HJM, Fehrmann RSN, de Bont ESJM, Hofstra RM, Gerbens F, Kamps WA, de Vries EG, van der Zee AG, te Meerman GJ and ter Elst A: Evidence based selection of housekeeping genes. PLoS One 2: e898, 2007.

36. Fusco A, Grieco M, Santoro M, Berlingieri MT, Pilotti S, Pierotti MA, Della Porta G and Vecchio G: A new oncogene in human thyroid papillary carcinomas and their lymph-nodal metastases. Nature 328: 170-172, 1987.

37. Nikiforov YE: RET/PTC rearrangement in thyroid tumors. Endocr Pathol 13: 3-16, 2002.

38. Nikiforov YE: Thyroid carcinoma: Molecular pathways and therapeutic targets. Mod Pathol 21 (Suppl 2): S37-S43, 2008.

39. Plaza-Menacho I, Burzynski GM, de Groot JW, Eggen BJL and Hofstra RMW: Current concepts in RET-related genetics, signaling and therapeutics. Trends Genet 22: 627-636, 2006.

40. Mcllwain DR, Berger T and Mak TW: Caspase functions in cell death and disease. Cold Spring Harb Perspect Biol 5: a008656, 2013.

41. Fracchiolla NS, Bamonti Catena F, Novembrino C, Ippolito S, Maisonneuve P and Cortelezzi A: Possible association between reactive oxygen metabolites and karyotypic abnormalities in myelodysplastic syndromes. Haematologica 88: 594-597, 2003. 
42. Mittler R, Vanderauwera S, Suzuki N, Miller G, Tognetti VB, Vandepoele K, Gollery M, Shulaev V and Van Breusegem F: ROS signaling: The new wave? Trends Plant Sci 16: 300-309, 2011.

43. D'Autréaux B and Toledano MB: ROS as signalling molecules: Mechanisms that generate specificity in ROS homeostasis. Nat Rev Mol Cell Biol 8: 813-824, 2007.

44. Antoszczak M, Maj E, Stefańska J, et al: Synthesis, antiproliferative and antibacterial activity of new amides of salinomycin. Bioorganic Med Chem Lett 24: 1724-1729,

45. Gujral TS, van Veelen W, Richardson DS, Myers SM, Meens JA, Acton DS, Duñach M, Elliott BE, Höppener JW and Mulligan LM: A novel RET kinase- $\beta$-catenin signaling pathway contributes to tumorigenesis in thyroid carcinoma. Cancer Res 68: 1338-1346, 2008.

46. Lu D, Choi MY, Yu J, Castro JE, Kipps TJ and Carson DA: Salinomycin inhibits Wnt signaling and selectively induces apoptosis in chronic lymphocytic leukemia cells. Proc Natl Acad Sci USA 108: 13253-13257, 2011.

47. Lu W, Lin C, Roberts MJ, Waud WR, Piazza GA and Li Y: Niclosamide suppresses cancer cell growth by inducing Wn co-receptor LRP6 degradation and inhibiting the Wnt/ $\beta$-catenin pathway. PLoS One 6: e29290, 2011.

48. Chen M, Wang J, Lu J, Bond MC, Ren XR, Lyerly HK, Barak LS and Chen W: The anti-helminthic niclosamide inhibits Wnt/Frizzled1 signaling. Biochemistry 48: 10267-10274, 2009.

49. Hong D, Ye L, Gagel R, Chintala L, El Naggar AK, Wright J and Kurzrock R: Medullary thyroid cancer: Targeting the RET kinase pathway with sorafenib/tipifarnib. Mol Cancer Ther 7 : 1001-1006, 2008.

50. Markowitz JN and Fancher KM: Cabozantinib: A multitargeted oral tyrosine kinase inhibitor. Pharmacotherapy 38: 357-369, 2018.

51. Cooper MR, Yi SY, Alghamdi W, Shaheen DJ and Steinberg M: Vandetanib for the treatment of medullary thyroid carcinoma. Ann Pharmacother 48: 387-394, 2014.
52. Yakes FM, Chen J, Tan J, Yamaguchi K, Shi Y, Yu P, Qian F, Chu F, Bentzien F, Cancilla B, et al: Cabozantinib (XL184), a novel MET and VEGFR2 inhibitor, simultaneously suppresses metastasis, angiogenesis, and tumor growth. Mol Cancer Ther 10: 2298-2308, 2011

53. Maliszewska A, Leandro-Garcia LJ, Castelblanco E, Macià A, de Cubas A, Goméz-López G, Inglada-Pérez L, Álvarez-Escolá C, De la Vega L, Letón R, et al: Differential gene expression of medullary thyroid carcinoma reveals specific markers associated with genetic conditions. Am J Pathol 182: 350-362, 2013.

54. Yang D, Wang C, Luo Y, Li X, Song Q, Zhang J and Xin S: Activated E2F activity induces cell death in papillary thyroid carcinoma K1 cells with enhanced Wnt signaling. PLoS One 12: e0178908, 2017.

55. Malumbres M and Barbacid M: Cell cycle, CDKs and cancer: A changing paradigm. Nat Rev Cancer 9: 153-166, 2009.

56. Bertoli C, Skotheim JM and de Bruin RAM: Control of cell cycle transcription during G1 and S phases. Nat Rev Mol Cell Biol 14: 518-528, 2013.

57. Kim KY, Park KI, Kim SH, Yu SN, Park SG, Kim YW, Seo YK, Ma JY and Ahn SC: Inhibition of autophagy promotes salinomycin-induced apoptosis via reactive oxygen species-mediated PI3K/AKT/mTOR and ERK/p38 MAPK-dependent signaling in human prostate cancer cells. Int J Mol Sci 18: E1088, 2017.

58. Kim SH, Choi YJ, Kim KY, Yu SN, Seo YK, Chun SS, Noh KT, Suh JT and Ahn SC: Salinomycin simultaneously induces apoptosis and autophagy through generation of reactive oxygen species in osteosarcoma U2OS cells. Biochem Biophys Res Commun 473: 607-613, 2016.

59. Polakis P: Wnt signaling and cancer. Genes Dev 14: 1837-1851, 2000.

60. Fahim M, del Valle G and Pressman BC: Comparison of the effects of the ionophore salinomycin and adrenaline on the haemodynamics and work efficiency of the dog heart. Cardiovasc Res 20: 145-152, 1986. 